\title{
Application of Artificial Neural Networks in Hydrological Modeling : A Case Study of Runoff Simulation of a Himalayan Glacier Basin
}

\author{
A.M. Buch \\ E-Mall : ambuchesac.ernel.in \\ Remole sensing Appllcallons Group \\ Space Appllcations Contre (ISRO) \\ Anmedabad 380-053 (INDIA)
}

A. Narain $\quad$ P.C. Pandey

\section{Abstract}

The simulation of runoff from a Himalayan Glacier basin using an Artificial Neural Network (ANN) is presented. The performance of the ANN model is found to be superior to the Energy Balance Model and the Multiple Regression model. The RMS Error is used as the figure of merit for judging the performance of the three models, and the RMS Error for the ANN model is the least of the three models. The ANN is faster in learning and exhibits excellent system generalization characteristics.

\section{Introduction}

Central Asia, the main regime of mountain glaciation in the Himalayas, is notable for its diversity of hydrological and meteorological conditions. As the largest ice-sheet outside the polar regions, it nourishes some of the largest river systems, like the Indus, the Ganges, etc. These mountain rivers have as their source the liquid run-off from melting snow and ice as well as liquid precipitation into their drainage basins. However, for most of the river systems in the central Asia, the water from melting is the main source of nourishment.

The study of the glaciated mountainous areas presents many difficulties, due to both lack of information on the water balance elements and the great variety and complexity of natural conditions of these areas. The structure of natural zones of ablation ( and consequently the water balance) is determined by geographical position and the peculiarities of orography, the absolute and relative height of mountains, the circulation processes and radiation regime, the exposition of slopes, the geological structure, etc. [7]

There exist many empirical methods of simulating and predicting glacier melt runoff, 
including time series modeling and actual physical parametric modeling. one of the most widely studied and viable method is the Energy-Balance Model. This method has been advocated by various researchers for operational runoff forecasting from glacierized basins. [3], [4], [10]

\section{The study Area}

The Chhota Shigri glacier is a medium size valley glacier situated in the Lahaul and spitti District of Himachal Pradesh (India). The glacier lies between latitudes 77-29N and $77-33 \mathrm{~N}$ and longitudes 32$11 \mathrm{E}$ to $32-18 \mathrm{E}$, covering an area of about $19.39 \mathrm{sq}$. $\mathrm{km}$. Geologically this area is confined to the Rohtang gneissic complex of the central Crystalline of the higher Himalaya. Fig. 1 (a) shows various features of the glacier and Figure 1 (b) shows relevant hydrogeomorphological parameters. [1]

\section{The Energy Balance Model}

Marks and Dozier (1992) have carefully analyzed the various types of heat fluxes and their relative influence over the snow melt run-off process in a small alpine basin. They have clearly demonstrated the dominance of solar radiation heat flux and two other important fluxes, viz. the sensible heat flux, and the latent heat flux in the runoff calculations. This logic can be applied to other glaciated areas as well. Since the solar radiation is easily measured and the heat flux is easily

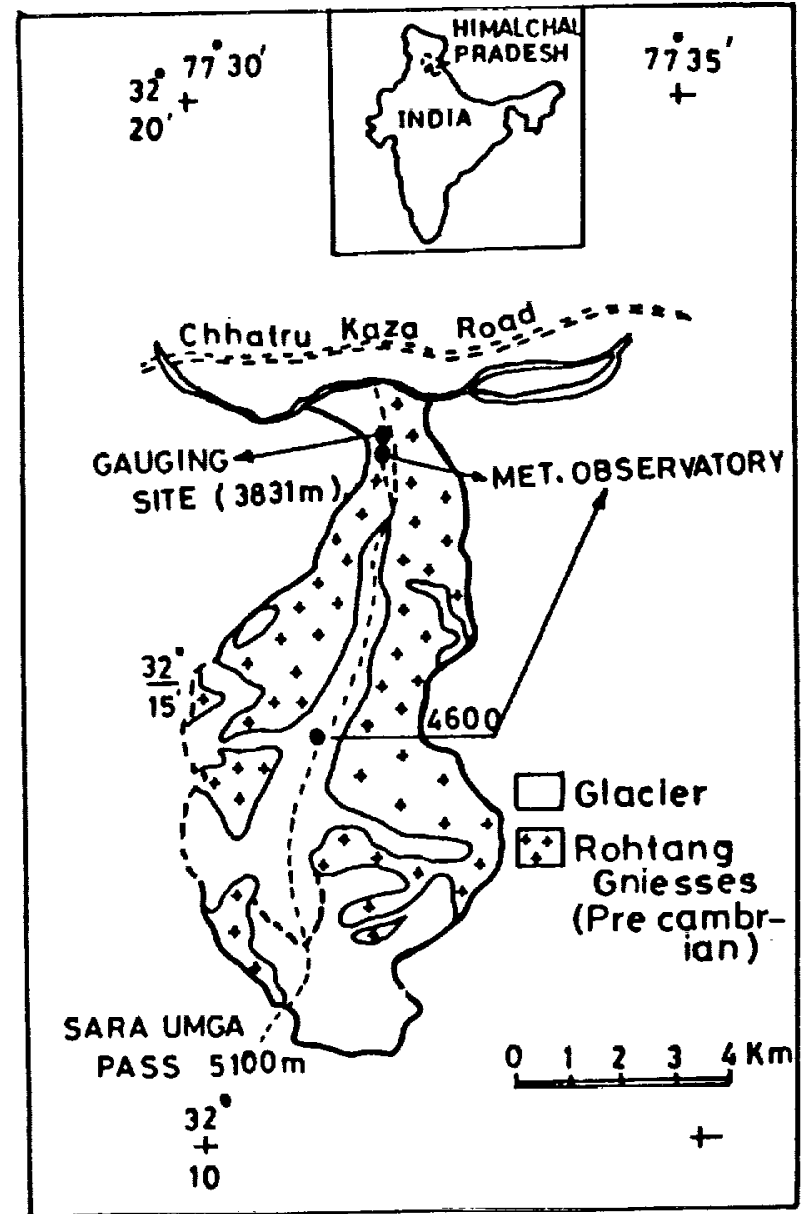

Figure 1 (a). Glacier Location Map
Total Area of the Glacler Accumulation Area Average Height of Acc. Area Ablation Area Average Helght of Abl. Area Accumulation Area Ratlo Maximum Glacier Height Snout Height Orientation Average Gradient Length of Glacier
19.39 sq. $\mathrm{km}$. $18.15 \mathrm{sq} . \mathrm{km}$. 5010 Mts. 1.24 sq. km. 4133 Mts.

0.91 5595 Mts. 3840 Mts. NNE $176 \mathrm{Mts} . / \mathrm{km}$. $10.00 \mathrm{~km}$.

(adopted from Dhaniu and Buch, 1989)

Figure 1 (b). Hydrogeomorphological Parameters 


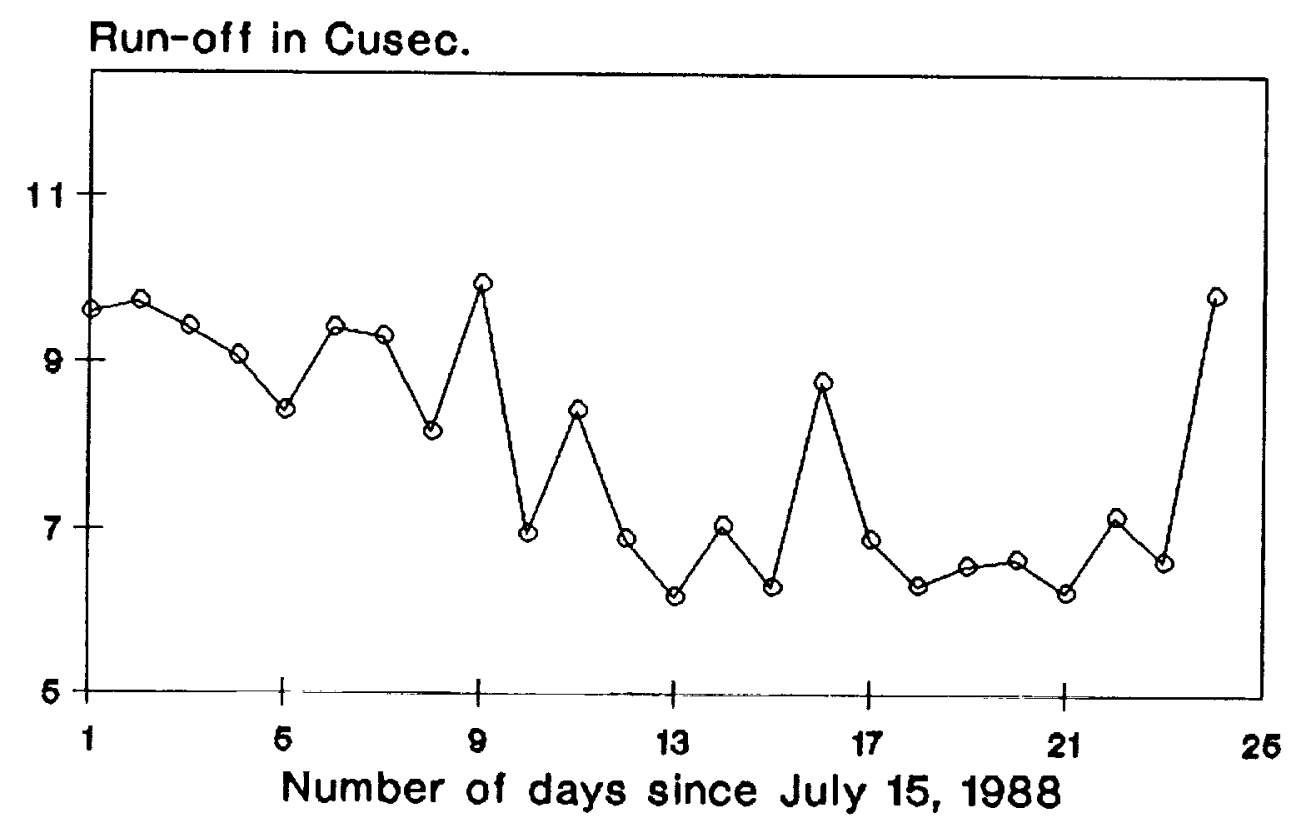

- Observed Runoff

Figure 2. Hydrograph of Chhota Shigri Stream

modeled for a given topography, it should be possible to reliably model the runoff from glaciated areas.

The energy budget for a melting glacier can be expressed as

$Q m=Q n+Q h+Q e+Q r-D$

Where

Qm = Energy flux actually available for melting the ice.

Qn $=$ Net radiation flux ( in Watts / Sq. Meter )

Qh $=$ sensible heat flux ( in Watts /.Sq. Meter )

Qe $=$ Latent heat flux ( in Watts / Sq. Meter)

Qr $=$ Sensible heat flux from rain. (This term is negligible in our case as no rain was observed during the period of this study.)

The net radiation flux is calculated as

Qn $=$ QSW + QIW

Where

Qsw = Shortwave radiation balance measured at the observatory, by net radiometer.

QlW $=$ Long wave radiation budget at the surface, modeled using the algorithm suggested by [13] .

The turbulent fluxes, viz. The Qh and Qe were determined using the standard aerodynamic formulae and the roughness length was assumed to be constant at $5 \mathrm{~mm}$ for this experiment. 


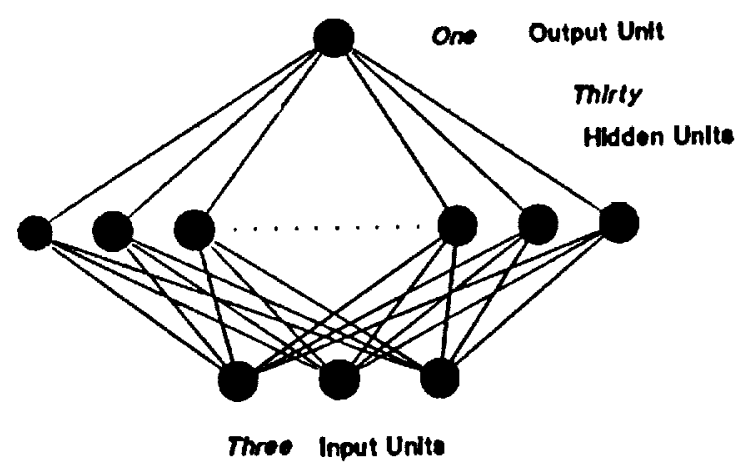

Figure 3. Neural Network Architecture used for Glacier Run-off Simulation

The hydrometeorological data and the net radiation flux data, along with corresponding runoff, were collected in situ during the chhota shigri Glacier Expedition in July August, 1988. The approach to this glacier is possible only during the ablation season, as the high mountain passes remain snow-covered for the rest of the period. This is the major bottle-neck in collecting long-term melt-discharge records for these areas. The Hydrograph of the chhota shigri melt-stream is shown in Figure 2.

The data are sparse and call for a technique that can generalize the latent system configuration to improve their applicability to runoff calculations. One such recent technique that possesses excellent generalization characteristics in addition to very good learning capability is the Artificial Neural Network technique.

Modeling Physical systems and Processes using Artificial Neural Networks
Many of our research efforts in the field of Remote sensing remain directed towards understanding and developing mathematical models that can simulate dynamic physical processes in oceans, atomosphere and the environment in general. The spacecrft-based sensors provide much-needed details about various parameters that govern these processes. However, due to limited knowledge of the physical processes in the environment, and the inherent noise in many geophysical data, environmental systems often cannot be accurately represented through numeric values describing their physical properties and interactions, but rather are subjected to categorisation into broad classes. [9]

The modelers have been investigating many different techniques to exactly simulate the processes from the previous knowledge, available in terms of historic data (very good survey of recent tachniques is provided by Tsonis and Elsner, 1989). Many efforts to model dynamic systems have been undermined by the system's inherent chaoticity in the data. One solution is to model the temporal variability of a parameter rather than the parameter per se. [2]

\section{Neural Network Architecture used for Runoff simulation}

Recently, there has been a great surge in the application of multi-layer-feed-forward Artificial Neural Networks to diverse system identification problems [2], [11], [5]. In 


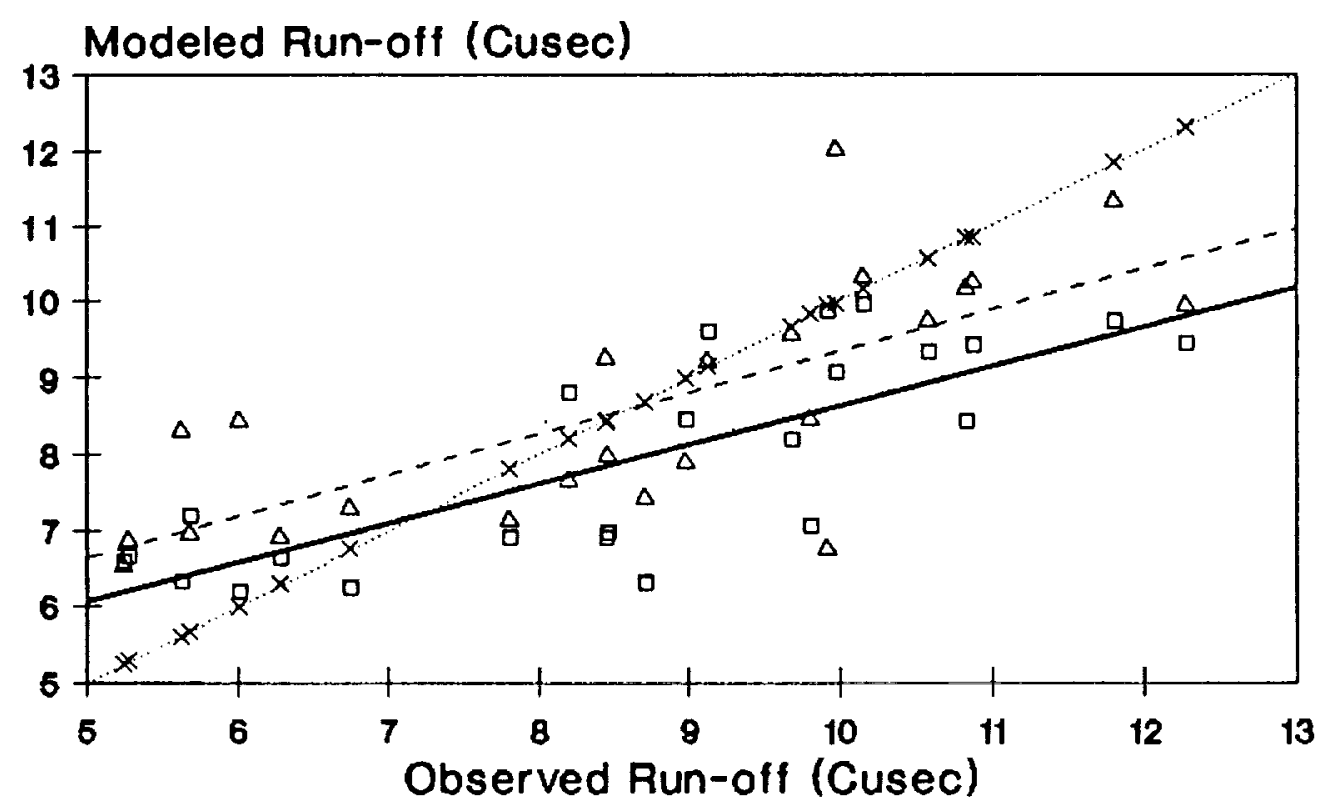

$\rightarrow$ Energy Balanoe Model $\triangle$ Mulllple-regreselon $\times$ ANN Model

Figure 4. Comparative Model Performance

this study,

Fast-Back-Error-Propagation

algorithm has been used. [6]

The network for run-off prediction comprises 3 layers, viz. the input layer, the hidden layer and the output layer. The input layer consists three input neurons corresponding to three heat fluxes viz. the solar Radiation Heat Flux, the Sensible Heat Flux and the Latent Heat Flux. The hidden layer has 30 nodes, and the output layer consists of one neuron corresponding to the modeled run-off value. The schematic diagram is shown in Figure 3 .

\section{Generalisation Performance of ANN Model}

Generalisation is a measure of how well the network performs on the actual problem once the training is complete.

The standard method for measuring the generalisation characteristics of a given model is called the method of 'Cross Validation'. The method splits the data set into two subsets, viz. the training data set and the testing data set. The learning is performed using the training data set and the network performance is evaluated using the test data set. Unless the training set is large enough, the performance of the network on training data is not likely to be an accurate measure of its performance on future or unknown data.

To achieve a statistically significant result, several independent splits are required and the average of the results is accepted as the overall 


\begin{tabular}{|lc|}
\hline Model & RMS Error \\
\hline Energy Balance Model & 1.46 \\
Multiple Regression Model & 1.54 \\
ANN Model ( 1391 Iter ations ) & 0.06 \\
\hline
\end{tabular}

Figure 5. Table Showing Modeling Errors

performance of the network. While the cross validation method is a widely accepted method, it is extremely timeconsuming in the case of ANN as lenghty training times are required for each independent partition of the data set.

In the case of the Himalayan glacier basins, the hydrometeorological data collected in situ are sparce, as the mountain passes leading to the glacier snout remain open for a very short period towards the end of summer. Hence, all of the data sets have to be used for meaningful training. Thus there is a need for alternate reliable methods for predicting the generalisation performance of the network without having a test data set.

An alternative technique which requires far fewer computations is called the 'Predicted Squared Error' technique. This technique relies on statistical methods to derive an expression for the generalisation performance of a system as a function of its performance on the training data set, the number of free parameters in the system and the size of the training data set. [5]

$\mathrm{PSE}=\mathrm{MSE}+(2 \star \mathrm{NW} / \mathrm{Np}) \star(\mathrm{r} 2)$

Where

PSE $=$ Pridicted squared Error. ( For Future)

MSE = Mean Squared Error of the training data set.

$\mathrm{NW}=$ Number of free parametres in the model (120 in our case).

$\mathrm{Np}=$ Number of training patterns for the model $(24$ in our case).

(r2) = variance of the noise determined by the formula:

$(\mathrm{r} 2)=\operatorname{abs}[(\mathrm{p} /(\mathrm{p}-\mathrm{Nw})) * \mathrm{MSE}]$

Where

$p=$ Number of patterns used for training the network.

The MSE in the ANN model for the Chhota Shigri Runoff Model is estimated at 0.0036 . Hence by substituting the values in eq. 4 and eq. 3 we get the PSE as 0.0126 , which is quite acceptable as model error considering the paucity of data.

\section{Conclusions}

Figure 4 depicts the resultant calculated runoff from the energy balance model against two other models, viz. the Multiple-Regression Model, the Energy Balance Model and the ANN model. (See Figure 5)

It can be clearly seen from the 
comparative performance of the three different models that the trained ANN model assumes the flow values that are closest to in situ measured values. (The Correlation Coefficient between the measured runoff and the runoff simulated by ANN model is of the order of 0.9998) Currently, we are investigating the application of different ANN models to diverse hydrological and meteorological simulation and forecasting problems.

The technique of system modeling with ANN holds very good promise. However, it requires rigorous research and simulations before any operational model can be developed.

\section{Acknowledgements}

The authors are grateful to Mr. N.D. Sen, School of Environmental Sciences, Jawaharlal Nehru Univesity, New Delhi, for providing Hydrometeorological Data and Energy Balance Model output for the Chhota Shigri Glacier.

\section{References}

(1) Dhanju, M.S. and Buch, A. (1989) "Remote Sensing of Himalayan Glaciers.", Proc. National Meet on Himalayan Glaciology, June 1989, pp. 193-213.

(2) Elsner, J.B. and Tsonis, A.A. (1992) " Non-linear Prediction, Chaos and noise.", Bulletin of the American Meteorological society, Vol. 73 , No. 1, pp. 49-60.
Gottlieb,
L .
(1980)

"Development and application of a run-off model for snow covered and glacierized basins.", Nordic Hydrology (II), pp. $225-272$.

(4) Hay, J.E. and Fitzharries, B.B. (1988) "A comparison of energy balance and bulk aerodynamic approaches for glacier melt." Journal of Glaciology, Vol. $34, \mathrm{pp}$. 145153 .

(5) Hush, D.R. and Horne, B.G. (1993) " Progress in Supervised Neural Networks", IEEE Signal Proc. Meg., Vol. 10, No. 1, pp. 8-39.

(6) Karayiannis, N.B. and Venetsanopoulous, A.N. (1992) "Fast Learning Algorithms for Neural Networks.", IEEE Tras. on circuits and systems-II Analog and Digital signal Processing, Vol. 39, No. 7, pp. 453-474

(7) Lvovich, M.I. and Tsigelnaya, I.D. (1971), "A method of studying the water balance and estimating the water resources of glacial mountain areas.", Proc. of the Moscow Symposium, 1971.IASH, pp. 229-232.

(8) Marks, D. and Dozier, J . (1992), "Climate and Energy exchange at snow surface in the Alpine Region of Sierra Nevada, 2 , Snow Cover Energy Balance.", Water Resources Research, Vol. 28, No. 11, pp. 3043-3054.

(9) Maslanik, J.A. and Schweiger, A.J. (1989) "Classification of Merged AVHRR and SMMR arctic data with Neural Networks.", PE \& RS, Vol. 55, No.9, pp. 1331-1338. 
(10) Moore, R.D. and Owens, I.F. (1984), "Controls on advective snow-melt in a maritime alpine basin.", Journal of Climate and Applied Meteorology.", Vol. 23, pp. 135-142.

(11) Tsang, Leung.'
Zhengxiao. Chen,
(1992), "Inversion of Snow
Parameters from
Microwave Passive
Measurements by Neural Network
trained with a
Scattering Model.", IEEE Trans.
on Geoscience and Rultiple

Sensing, Vol. 30, No. 5, pp. 1015-1024.

(12) Tsonis, A.A. and Elsner, J.B. (1989), "Chaos, non-linear attractors and weather.", Bulletin of the American Meteorological Society, Vol. 70, pp. 545-547.

(13) Upadhyay, D.S., Chaudhary, J.N. and Katyal, K.N. (1983) "An ampirical model for prediction of snowmelt runoff in sutlej." Proc. of Ist Nat. symp. on seasonal snow cover, V. II, pp. 129-142 


\section{Monitoring, Control, and Diagnosis}


